\title{
Design and implementation of the anti-cancer communication platform based on B/S structure
}

\author{
Qiang $\mathrm{Li}^{1}$ \\ Department of General Surgery, \\ Zhujiang Hospital,Southern Medical University, \\ Guangzhou, 510282, China \\ Rousseau2000@163.com
}

\begin{abstract}
Current information on the web about the cancer is numerous and complex. Cancer patients is difficult to find the information they need quickly. To help cancer patients to access relevant information effective, thus building this anticancer communication platform. The platform can allow cancer patients to understand the pathological sense of a cancer disease better. And help cancer patients to treat actively. The anti-cancer communication platform using ASP.NET, Visual Studio.NET 2010 as a development tool, SQL2008 database. Specifically including cancer exchange forum, common cancers pages, anticancer knowledge forum, Healthy Living Forum and other platform management section.
\end{abstract}

Keywords-Cancer; communication platform;Preventive treatment;Asp.net

\section{INTRODUCTION}

With the incidence of cancer increased year by year, the site about cancer are more and more, such as our authoritative cancer-related websites: http://www.cn-cancer.com 、 http://www.aizheng.net. And foreign authoritative Cancer Network such as http://www.cancer.gov[1].Building related cancers websites can make cancer patients have more opportunity to learn the latest information about their disease. The purpose of this design is to develop a common platform for cancer, a platform to focus on the user's information of exchange help and psychological health[2].And the patient can quickly browse each section to find the information they need to overcome psychological difficulties and improve the quality of healthy living. [3] [4]

\section{RELATED TECHNOLOGIES}

This paper describes the system is mainly use t Asp.net technology to display the page. Asp.net technology today is popular. Because the system is based on B /S model to develop, so use Visual Studio.Net 2010 as a server system for running. Taking into account the system's ease of operation, the database use SQL Server 2008 as data management system.SQL Server is a relational database management system which is launched by Microsoft. SQL Server is a database product with full Web support. SQL Server provides Extensible Markup Language (XML) support. [5]

\author{
Zheng Xiang ${ }^{2 *}$ \\ College of Medical Information Engineering, \\ Guangdong Pharmaceutical College, \\ Guangzhou, 510006, China \\ Wartime2000@163.com
}

\section{SYSTEM DESIGN}

\section{A. System feature modular design}

By finding relevant information to summarize several aspects of cancer patients in need of the following: the clinical manifestations of cancer diseases, treatment and diagnosis, early signs of cancer and the common symptoms of cancer, cancer causes and so on. System is divided into front and back modules according to system functional requirement analysis. Backend modules include anticancer title block, cancer submodule title, registered users management module, system users management module, the announcement module, etc. Anticancer title module main function is to add the information of names and notes of anticancer title. The main function of anticancer title sub-module is to add the information of names and notes of anticancer subtitle. The main function of a registered user management module is to view a list of users and view user details. The main function of the system management module is to add the system administrator and delete unneeded administrator. Announcement module main function is to publish information bulletin reception. Reception module includes five modules, anticancer communication module, common cancer module, a-cancer knowledge module, healthy living module and anticancer platform management module. Fig.1 shows system function module. [6] [7]

\section{B. Sign in Process Analysis}

In this communication platform, different users have different permissions. It is necessary to enter a different page according to different user roles. If you are a system administrator login, it appears as admin page. If you are a general user login, you can only browse the Web. If you are a registered user login, you can browse the web and c post a message. Through the implementation of the whole process analysis platform, you

can get the entire login process anticancer platform.

\section{Database Design}

Database design is a very critical aspect in system design, which is the basis for the user interface layer and business logic layer. Good database design can improve the efficiency of data storage systems to ensure data integrity and unity, but also can improve the scalability of the system. Typically include database requirements analysis, database design concepts and logical structure design. Anticancer exchange platform is 


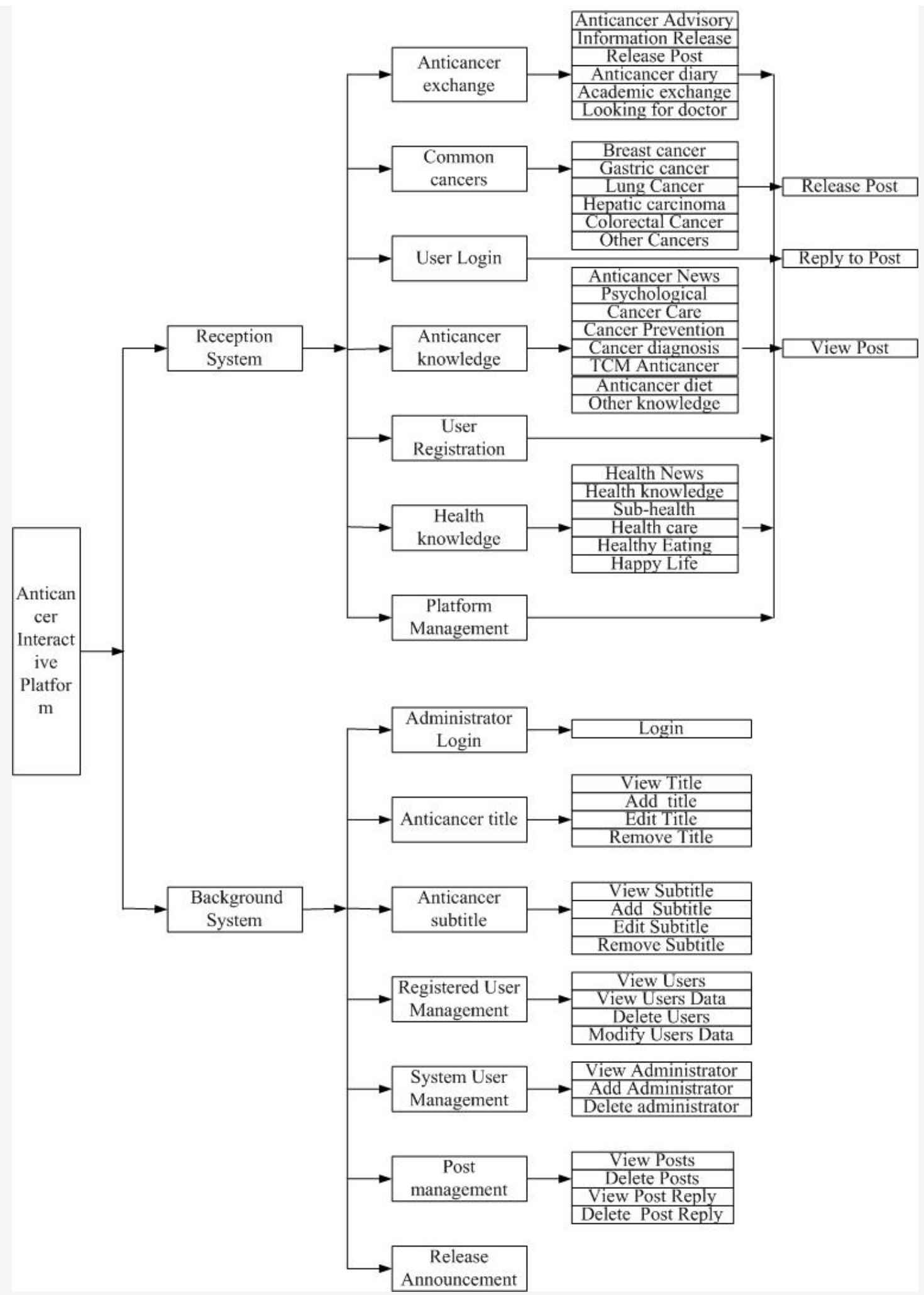

Fig.1 System function module 
TABLE1. USER INFORMATION TABLE

\begin{tabular}{ccccc}
\hline Field Name & Description & Field Type & FieldLength & Allowempty \\
\hline ID & User ID & int & 4 & Not Null \\
\hline UserName & Username & nvarchar & 50 & Null \\
UserPass & User password & nvarchar & 50 & Null \\
UserNicke & Nickname & nvarchar & 50 & Null \\
Usersex & Sex & nvarchar & 50 & Null \\
Useremail & E-mail & nvarchar & 50 & Null \\
UserQQ & QQ & nvarchar & 50 & Null \\
Userphone & Phone & nvarchar & 50 & Null \\
UserMSN & MSN & nvarchar & 50 & Null \\
UserPostCode & PostCode & nvarchar & 50 & Null \\
UserProfession & Profession & nvarchar & 50 & Null \\
UserHobby & Hobby & ntext & 16 & Null \\
Useraddress & Address & ntext & 16 & Null \\
\hline
\end{tabular}

TABLE2. ANTICANCER TitLe TABLE

\begin{tabular}{ccccc}
\hline Field Name & Description & Field Type & FieldLength & Allowempty \\
\hline Big_ID & $\begin{array}{c}\text { Anticancertitle } \\
\text { number }\end{array}$ & int & 4 & Not Null \\
\hline BigName & $\begin{array}{c}\text { Anticancer title } \\
\text { Remarks } \\
\text { Bnformation }\end{array}$ & varchar & 50 & Null \\
BigInfo & text & 16 & Null \\
\hline
\end{tabular}

TABLE3. ANTICANCER SUBTITLE TABLE

\begin{tabular}{|c|c|c|c|c|}
\hline Field Name & Description & Field Type & FieldLength & Allowempty \\
\hline Small_ID & $\begin{array}{c}\text { Anticancer subtitle } \\
\text { number }\end{array}$ & int & 4 & Not Null \\
\hline Small_Name & $\begin{array}{c}\text { Anticancer subtitle } \\
\text { name }\end{array}$ & nvarchar & 50 & Null \\
\hline Small_Info & $\begin{array}{c}\text { Anticancer subtitle } \\
\text { information }\end{array}$ & ntext & 16 & Null \\
\hline Big_ID & $\begin{array}{c}\text { Anticancer title } \\
\text { number }\end{array}$ & int & 4 & Not null \\
\hline
\end{tabular}

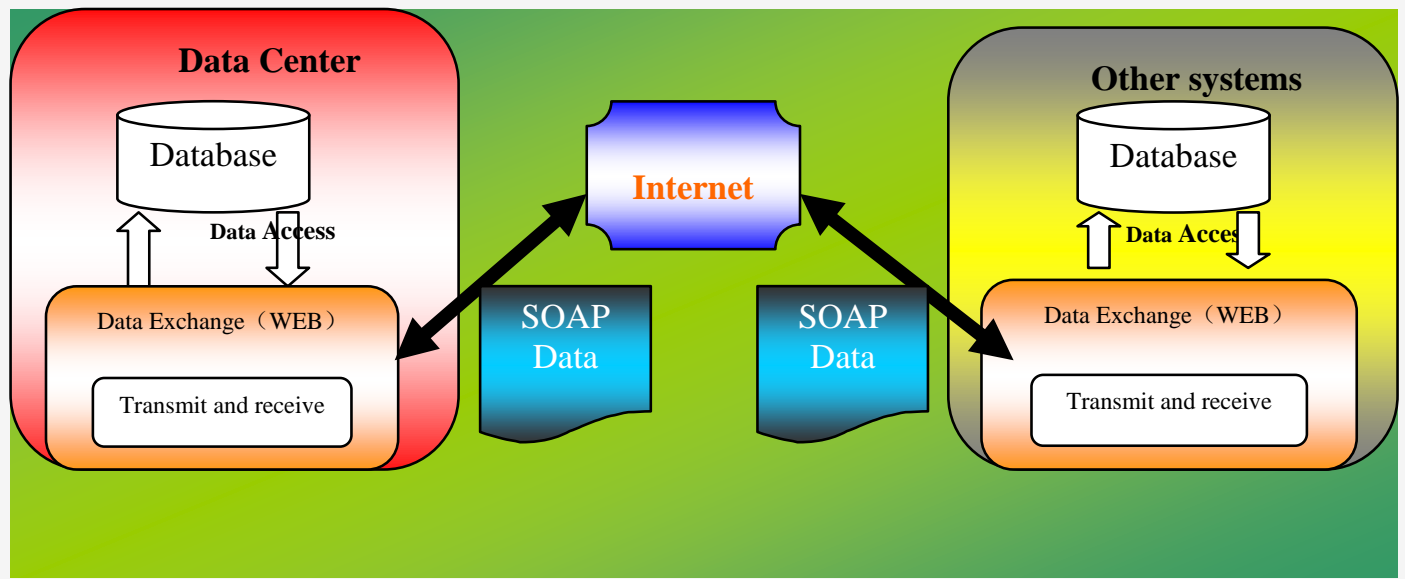

Fig.2 Data exchange principle 
post reply message, bulletin information, system administrator information, and other data management information. Registered user information management includes to view and modify the login password and recover of a registered user. Anticancer title information management includes to add the title and to see the name of anti-cancer information and notes, or edit, update, delete. Post information management, including a list of registered user postings, content viewing, and deleting posts. Post reply information management, including registered user postings reply list, content viewing, and deleting posts reply. Notice information includes system administrators bulletin issued by the title and content. We can get the whole E-R diagram by analyzing the demand for anti-cancer analysis and data exchange platform processes. According to the database requirements analysis and conceptual design of the above, we can design well-known database called KangAi by SQL Server 2008 database, KangAi database is composed by multiple tables below, User information table (Table.1), Anticancer title table (Table.2), Anticancer subtitle table (Table.3), Post information table, Administrator information table, Announcement information table, Reply information table, Peer Review information table, Message table, Information table. Each table is shown below. Each table corresponds to a table in the database. [8][9]

\section{DISTRIBUTED IMPLEMENTATION}

This system is a distributed system that will involve the existing information for data exchange and sharing. WEB services have been widely accepted by the industry to solve complex problems and distributed processes across multiple platforms and systems. Data exchange principle is given as Fig.2 shows.

\section{REALIZATION OF THE SYSTEM}

The anticancer exchange platform is based on the three-tier structure of B /S mode, its processing is distributed shared by the presentation layer, application logic and data layers. User sends a request to a server on the network distributed through the browser, the server access the database for the browser's request by ADO.NET mode. The required information is returned to the user in the form Html browser.User interface for the users to display interact information between the system and the users. Anticancer Platform is related to anticancer home page, the user registration page, the user login page, the posting page, post replies page, all posts page, platform administrator login page and other platform manage page. This system design is very usefull for the user to access the information they need .It has a good practical significance and value.

\section{ACKNOWLEDGMENT}

Author Qiang Li, and Zheng Xiang contribute equally. I would like to declare on behalf of my co-authors that the work described was original research that has not been published previously, and not under consideration for publication elsewhere, in whole or in part. All the authors listed have approved the manuscript that is enclosed. This work is supported in part by The science and technology plan of Guangdong province(NO.2012B060500063),China.

\section{REFERENCES}

[1] Wang Xiuli, Huangxue Wei. "information needs of cancer patients with the diagnosis".Henan University, 2002 (3): 5-10.

[2] Wu Heping. “ psychological characteristics of cancer patients and rehabilitation".Central Plains Medical Journal, 2004,31 (4): 53-54.

[3] Li Hongmei, Li Qiuping. “information needs of patients with cancer research progress ”.Journal of Nursing, 2008 (20):71-73.

[4] Huangxue Wei, Wang Xiuli. "information needs of cancer patients”.China Health Journal Information, 2001 (4): 265-270.

[5] Chen Li. "communicate effectively in cancer patients and their families ". modern medicine, 2006,22 (16): 7-9.

[6] Chen Wei, Wei Lini. “ASP.NET3.5 web development tutorial examples ”.Beijing:Tsinghua University Press, 2009.

[7] Dino Esposito "Proficient in ASP.NET programming ”.Beijing::Tsinghua University Press, 2006.

[8] HanwanJiang. “SoftwareEngineering”.Beijing:Mechanical Industry Press, 2010.

[9] Maode Xiang, Luo Ge. "Web application design model based on three ASP.net technology ".Microcomputer Applications, 2002 (3): 26-28. 